\title{
Clinical Case of Mixed Infection: Tick-borne Encephalitis and Borreliosis in the Republic of Sakha (Yakutia)
}

\author{
Paraskovya S. Dyachkovskaya ${ }^{1, *}$
}

\begin{abstract}
${ }^{I}$ North-Eastern Federal University named after M.K. Ammosov, Medical Institute, Yakutsk, 677000, Russia, ${ }^{*}$ Corresponding author. Email: d-ya.ps@yandex.ru
\end{abstract}

\begin{abstract}
Tick-borne encephalitis is one of the most relevant natural-focal diseases in the Russian Federation. This article describes a clinical case of mixed infection: tick-borne encephalitis and borreliosis in the Republic of Sakha (Yakutia) in a man living in Yakutia. The greatest activity of ticks is in the first half of summer in the Republic of Sakha (Yakutia). Most contact with ticks involves visiting a forest area for relax. Given the identified features of the course of infection, primary specialists require caution about this disease, competently carry out early diagnosis and prescribe adequate therapy in a timely manner. Of great importance for the diagnosis of tick-borne infection is a carefully collected epidemiological history, with clarification of all possible routes of transmission of infection, as well as the presence of vaccination with compliance with the scheme and timeline.
\end{abstract}

Keywords: mixed infection, tick-borne encephalitis, borreliosis, Republic of Sakha, Yakutia

\section{INTRODUCTION}

The relevance of tick-borne infection remains in Russia due to the possibility of developing severe forms of the disease, leading to persistent disability and fatalities, which are recorded annually. Over the past decade, from 2000 to 3700 cases of tick-borne viral encephalitis have been recorded annually in the Russian Federation [12].

Natural foci of tick-borne encephalitis are widespread in the forest, forest-steppe landscape areas of the temperate climatic zone in the vast territory of Eurasia from the Atlantic to the Pacific Ocean. Recently, new territories endemic to tick-borne encephalitis have been identified in Japan, the Netherlands, and, in 2019, in the United Kingdom. The increasing risk of disease due to the development of tourism and visits to natural foci of tick-borne encephalitis has become an international public health problem [1].

In recent years, the number of differences in the course of tick-borne encephalitis in Russia and other European countries is narrowing. The area of the spread of ticks and tick-borne encephalitis virus subtypes is increasing. More severe cases began to occur in Europe [15].

In recent years, the problem of mixed infections carried by ixodid ticks has become very urgent, among which the most common are tick-borne encephalitis and ixodid tick-borne borreliosis [7].

Tick-borne encephalitis and tick-borne borreliosis are widespread neuroinfections characterized by possible severe lesions of the nervous system [6].

The main route of tick-borne encephalitis infection is transmissive one. Alimentary route has been recorded at varying frequency in different years, however, currently, it has not exceeded $7 \%$ in the total number of cases $[3,4,8]$. It possibly is conditioned by the fact that the Russian population consumes cow's milk more often than goat's or sheep's milk. Meanwhile, cow's milk is known to exhibit lesser risk of tick-borne encephalitis infection $[9,25]$. Many European farms keep goats and sheep, and sell unpasteurized milk of these animals to the people who lead a healthy lifestyle. Thus, it often results in occasional tick-borne encephalitis outbreaks, associated with the consumption of goat's and sheep's milk [20, 21, 23, 24, 29]. In Norway, a survey of farm 
cows shown that $88.2 \%$ of bovines had antibodies in their blood. This fact was regarded as a danger of foodborne contagion conditioned by the consumption of unpasteurized cow's milk in Norway [28].

Currently, published researches indicate the presence of features of the interaction of the causative agents of tick-borne encephalitis and tick-borne borreliosis in mixed infection $[10,13,14,26]$. At the same time, special attention is paid to the focal form of mixed tick-borne encephalitis-borreliosis infection, characterized by damage to the nervous system with the development of persistent neurological disorders and possible death [2, 16, 22, 27].

In 2018, 1,727 cases of tick-borne encephalitis were recorded in Russia (1.18 per 100 thousand population), 28 people died (1.6\% fatality). In 2019 , tick-borne encephalitis was diagnosed in 48 subjects, where 1,775 cases of the disease were recorded (1.21 per 100 thousand population). In 2019, 28 deaths from tickborne encephalitis were recorded (as in 2018). Fatalities are associated with the population's late request for medical care, untimely diagnosis, lack of a history of vaccination [18]

The Republic of Sakha (Yakutia) is not endemic to tick-borne encephalitis, however, the frequent attacks of ixodid ticks on the local population are recorded annually and every year it is spreading to the new territories. Cases of tick bites are registered not only in the border regions of South Yakutia, but also in the central, western and transfluvial regions. In 2010-2012, 2014 and 2019, the incidence of tick-borne viral encephalitis and tick-borne borreliosis was not recorded. In the spring-summer season of 2019, 221 cases of taiga ticks attacking people [19] were registered in the republic.

Despite the lack of recorded tick-borne encephalitis incidence in the Republic of Sakha (Yakutia), the detection of the seropositive patients with tick-borne encephalitis-specific antibody titer levels from 1:100 to 1:1600 among the unvaccinated population suggests the presence of tick-borne encephalitis foci in this area. However, to predict the patterns of the tick-borne encephalitis situation development on the territory of the Republic and to estimate the degree of its endemicity, it is necessary to study the abundance and level of infection of ixodid ticks, to identify the reservoirs of the tick-borne encephalitis virus in natural foci, to examine the immunity levels to the pathogen in farm animals and to continue the study of the immunological structure of the population [5].

Yakutia is a habitat to one species, which is Ixodes persulcatus, taiga tick. Earlier, this species inhabited the territory of South Yakutia, but currently, due to global warming, its range has expanded far to the north.
Yakutia has a harsh continental climate with average annual temperatures below zero, long and cold winters, which cause deep freezing of soil layers, and a small active layer in the short summer period. Long-term average January air temperatures in the central zone are up to $-51.2{ }^{\circ} \mathrm{C}$, in the southern - up to $-26.3{ }^{\circ} \mathrm{C}$. In summer, in most of the territory of Yakutia, the average monthly air temperature in July is $+23.2{ }^{\circ} \mathrm{C}$ with prolonged sunshine. The sum of air temperatures for the period when it is above $+10{ }^{\circ} \mathrm{C}$ characterizes the thermal resources of the warm season. In the central and southern zones, it is $1400-1600{ }^{\circ} \mathrm{C}$, which is enough for the evolvement of most insects and ticks. The region has little precipitation, mostly in summer $[11,17]$.

\subsection{Description of the subject of the article}

The article contains a description of the first clinical case recorded in the Republic of Sakha (Yakutia).

\section{PURPOSE OF THE RESEARCH}

is to study of the peculiarity of the course of mixed tick-borne encephalitis-borreliosis infection in the Republic of Sakha (Yakutia).

\section{MATERIALS AND METHODS}

Patient G., 45 years old, lives in the Olekminsky district of the Republic of Sakha (Yakutia). The patient had been under medical supervision since July 11, 2011.

Disease verification in the patient was carried out by combined serological studies on the antigens of the TBE virus and Borrelia burgdorferi. Immunological studies of blood sera for antibodies to TBE and Borrelia burgdorferi pathogens were carried out by enzyme immunoassay (ELISA) in the immunological laboratory of the Yakutsk Republic Clinical Hospital in Yakutsk.

\section{RESULTS AND DISCUSSION}

Patient G., 45, admitted to the infection department of the Republic Hospital in 11.07.18 with complaints of general weakness, moderate headaches, dizziness, weakness in the upper limbs. From a history of the disease: the patient noted a bite of 3-4 ticks in the neck on June 19, 2018. The tick was removed on its own and thrown away, as it was in the forest. He did not ask for medical help. In June 23, 2018 he found sucked ticks in the axillary region on the right, the tick was removed on its own and thrown away. He fell ill acutely in 25.06.2018: pain appeared in the back and chest; he did not pay attention to these symptoms. Since July 04, body temperature rose to $38{ }^{\circ} \mathrm{C}$, moderate headaches, nausea and vomiting appeared 2 times a day. $\mathrm{He}$ consulted the paramedical and midwifery station, where Cerukal (Metoclopramid) was injected, there was no improvement. He was sent to the Olekminsky central 
district hospital. From 05.07.2018 to 10.07.2018 he was in the infection department of the Olekminskaya Central District Hospital. 11.07.2018.

Epidemiological history: the disease cause can be connected with a tick bite to the cervical region. He denies contacts with infectious patients and the use of not boiled water. Living conditions: private house. Animals: 2 dogs. He was not vaccinated against tickborne encephalitis. He did not leave the republic. Family members are healthy.

The condition is regarded as severe. Body temperature was $36.1{ }^{\circ} \mathrm{C}$. Consciousness is preserved, contacted, sluggish, stalled. Position in bed: passive. The skin is clean, the color is normal, there is no rash. Visible mucous sclera of the eyes is normal. Subcutaneous fat is moderately developed. There are no bed sores. Lymph nodes are not enlarged, painless. Breathing is vesicular, no wheezing. Respiration rate $20 /$ min. Heart tones are rhythmic, muted. AD-120/80 $\mathrm{mm} / \mathrm{Hg}$, heart rate- $78 / \mathrm{min}$. The tongue is wet, covered with a fur. The abdomen during examination is normal, participates in the act of breathing. The abdomen with palpation is soft, painless, the liver and spleen are not enlarged. Bowel and bladder habits are without peculiarity. Symptoms of peritoneum irritation are negative. Peristaltic without features. Neurological status: Craniocerebral nerves without features; Pupils without changes $\mathrm{D}=\mathrm{S}$; Tongue: straight. Meningeal symptoms: occipital muscle rigidity -2 transverse fingers; Kernig's symptom is negative. There is no focal neurological symptomatology. Local status: in the axillary region there is a hyperemated spot on the right. No bite marks were found in the cervical region.

Taking into account clinical and epidemiological data, a diagnosis was made - tick-borne encephalitis. In the hospital, detoxification, antibacterial and symptomatic therapy, immunoglobulin against tickborne encephalitis $6.0 \mathrm{v} / \mathrm{m}$ No. 5 were carried out. A distinct improvement occurred after receiving immunoglobulin against tick-borne encephalitis after 3 days: headaches, dizziness were stopped, meningeal symptoms disappeared.

In the general blood test of 11.07.2018 - leukocytes $7.98 \times 109 / 1$, hemoglobin $134 \mathrm{gll}$, red blood cells $4.72 \times 1012 \mathrm{l}$, neutrophils $88.1 \%$, thrombocrit $0.20 \mathrm{~g} / \mathrm{l}$, platelets 275x109l, SOE-21 $\mathrm{mm} / \mathrm{h}$. Biochemical analysis - total protein - $63.2 \mathrm{~g} / \mathrm{l}$, albumin $-42 \mathrm{~g} / \mathrm{l}$, bilirubin total $-10 \mu \mathrm{mol} / 1$, blood glucose $-5.37 \mathrm{mmol} / \mathrm{l}$, urea $-7.7 \mathrm{mmol} / \mathrm{l}$, blood creatinine $-73 \mu \mathrm{mol} / \mathrm{l}$, ALT 18.9 u/l, ACT - 9.1 u/l; General urine test - SG 1020, protein - otrus, glucose, white blood cells - single.

Examination of cerebrospinal fluid from 09.07.2018 - Macroscopy: Quantity - $1.7 \mathrm{ml}$; Color - transparent, watery; Protein - $308 \mathrm{mg} / \mathrm{l}$; Glucose - negative;
Leukocytes in $1 \mathrm{~mm} 3-9 \mathrm{~mm} 3$. Microscopy: Leukocytes - 8-4-7, Erythrocytes altered - 1-1-0.

Abdominal ultrasound from 11.07.18, conclusion: minor diffuse changes in liver parenchyma. Seal the gallbladder wall. Diffuse changes in pancreatic parenchyma. Insignificant compaction of both kidneys.

ECG from 18.07.18, conclusion: sinus rhythm, heart rate -73 beats/min. Radiography of chest organs from 26.07.2018 g. Conclusion: no focal and infiltrative changes were detected in the lungs. Cerebral RCT of 27.07.2018, conclusion: no focal changes in brain structures were detected.

Immunological studies: The result of a blood serum study for antibodies to tick-borne encephalitis virus (TEC): 1. ELISA from 16.07.2018 - EEC antibodies IgM OP 3,117 detected; antibodies of VKE $\operatorname{IgG}$ it is revealed 1.226; anti-Lyme IgM OP 0.398 found; antiLyme IgG OP 0.155 found.

The patient was given the final clinical diagnosis: "Mixed tick-borne encephalitis-borreliosis infection: tick-borne encephalitis, a meningeal form of moderate severity; tick-borne borreliosis (serologically - antiLyme IgM detected)".

It was established that the patient in the acute period of the disease had a pronounced infectious-toxic syndrome with fever to febrile numbers. The patient's condition was regarded as a severe, positive symptom the rigidity of the occipital muscles. Subsequently, after the start of the use of immunoglobulin against tickborne encephalitis, the patient's condition improved: body temperature normalized, meningeal syndrome regressed. In addition to general-somatic and neurological examination, bacteriological examination of cerebrospinal fluid, ELISA, was used for etiological diagnosis. If necessary, additional diagnostic methods were used - chest radiography, ECG, ultrasound and computed tomography. Serological confirmation of the diagnosis "Mixed tick-borne encephalitis-borrelius infection received on the 12th day of the disease (specific class IgM antibodies to the TBE virus and borrelia were identified).

As a result of human immunoglobulin treatment against tick-borne encephalitis, as well as desensitizing, dehydration, antibacterial therapy, the patient showed positive dynamics of the disease course. The patient was discharged with recovery without neurological disorders and was sent for further treatment and supervision at the place of residence.

\section{CONCLUSION}

The greatest activity of ticks is in the first half of summer in the Republic of Sakha (Yakutia). Most contact with ticks involves visiting a forest area for relax. In order to highlight the prevention of tick-borne 
viral encephalitis, the need for immunization against tick-borne viral encephalitis among the population, sanitary and educational work is actively being carried out.

Given the identified features of the course of infection, primary specialists require caution about this disease, competently carry out early diagnosis and prescribe adequate therapy in a timely manner. Of great importance for the diagnosis of tick-borne infection is a carefully collected epidemiological history, with clarification of all possible routes of transmission of infection, as well as the presence of vaccination with compliance with the scheme and timeline.

Preventive measures for the tick-borne encephalitis include specific prevention (vaccination), emergency seroprotection (the use of human immunoglobulin) and non-specific prevention (vector control, use of personal protective equipment). Only the integrated approach to prevention can ensure maximum protection of the population.

\section{REFERENCES}

[1] E.I. Andaev, A.Ya. Nikitin, E.V. Yatsmenko et al., Trends in Epidemic Process Development of TickBorne Encephalitis in the Russian Federation, Laboratory Diagnosis, Prophylaxis and Forecast for 2021, Probl. of Particul. Danger. Infect. 1 (2021) 616. DOI: $10.21055 / 0370-1069-2021-1-6-16$

[2] L.I. Volkova, O.P. Kovtun, M.A. Tereshchuk, Clinical features of chronic tick-borne encephalitis and Kozhevnikov epilepsy in the Middle Urals, Rus. J. of Pediat. Neurol. 6(2) (2011) 3-10.

[3] V.M. Voronok, E. V. Zagney, The epidemiological situation of tick-borne encephalitis in Primorsky region, Health, Med. Ecol., Sce. 4(58) (2014) 126-131.

[4] S.G. Gerasimov, L.V. Smirnova, S.L. Razumovskiy, Epidemic situation of tickborne encephalitis in regions of Central Federal District of Russia, Infect. diseases: news, opinions, train. 8(4) (2019) 17-23. Retrieved from: https://doi.org/10.24411/2305-3496-2019-14002

[5] A.G. Dragomeretskaya, M.E. Ignatieva, O.E. Trotsenko et al., Condition of tick-borne viral encephalitis in nonendemic territory of the Republic of Sakha (Yakutia), Far Eastern J. of Infect. Pathol. 37 (2019) 27-29.

[6] A.P. Jerusalemsky, Tick-borne infections at the beginning of the 21st century, Neurol. J. 3 (2009) 16-21. ISSN: 1560-9545 eISSN: 2413-0699.

[7] N.M. Kolyasnikova, S.G. Gerasimov, A.A. Ishmukhametov et al., The evolution of tick-borne encephalitis over the 80-year period: the main manifestations, probable causes, Epidemiol. and Vaccine Prophyl. 19(3) (2020) 78-88. Retrieved from: https://doi: 10.31631/2073-3046-2020-19-3$78-88$

[8] O.N. Lubeznova, A.L. Bondarenko, The epidemiology of tick-borne infections on the north of Volga-Vyatka region, Med. almanac 2(26) (2013) 113-116.

[9] N.A. Morozov, E.A. Kashuba, M.D. Orlov et al., Tickborne encephalitis, Infect. diseases: news, opinions, train. 4 (2014) 13-20.

[10] T.V. Poponnikova, T.N. Vakhrameeva, T.Yu. Bedareva, G.Yu. Galieva, Cytokine profile in acute period of tick-borne neuroinfections in children, J. of Neurol. and Psychiatry named after S.S. Korsakov 110(5) (2010) 9-12.

[11] A.D. Reshetnikov, A.I. Barashkova, Z.S. Prokopev, Ixodid ticks (Ixodida: Ixodidae) of Yakutia, Theor. and pract. aspects of modern sci. 51 (2014) 141-143.

[12] T.F. Stepanova, E.A. Bragina, A.A. Katin et al., About possibility of tick-borne infections natural formation outside northern borders of taiga tick habitat, Public Health and Habitat 10(295) (2017) $50-55$.

[13] A. Subbotin, V. Semenov, V. Sokolov, D. Etenko, The main clinical manifestations of mixed tickborne encephalitis-borreliosis infection in adults, A doctor 13 (2011) 62-65.

[14] I.N. Udintseva, N.G. Zhukova, O.E. Chechin et al., Clinical-immunological characteristic of patients with tick-borne encephalitis in the acute period in the Tomsk region, Bull. of Siber. Med. 10(2) (2011) 44-49.

[15] E.O. Utenkova, N.A. Savinykh, Tick-borne encephalitis in Russia and Europe (review), Med. almanac 2(67) (2021) 13-21.

[16] D.A. Etenko, O.G. Gamov, A.V. Subbotin, V.A Semenov, Clinical aspects of transnosological comorbidity of tick-borne neuroinfections (tickborne encephalitis, borreliosis), Int. Med. Arch. 2 (2013) 41-45.

[17] M.K. Gavrilova, Climate of Central Yakutia, Yakutsk book publ. house, Yakutsk, 1973.

[18] On the sanitary and epidemiological situation in the Russian Federation in 2018: State report. Federal Service for Supervision of Consumer Protection and Human Welfare, 2019. Retrieved from: rospotrebnadzor.ru 
[19] On the sanitary and epidemiological situation in the Republic of Sakha (Yakutia) in 2019: State report. Federal Service for Supervision of Consumer Protection and Human Welfare, 2020. Retrieved from: rospotrebnadzor.ru

[20] S.O. Brockmann, R. Oehme, T. Buckenmaier et al., A cluster of two human cases of tick-borne encephalitis (TBE) transmitted by unpasteurised goat milk and cheese in Germany, May 2016, Euro Surveill 23(15) (2018) 17-00336. Retrieved from: https://doi.org/10.2807/1560917.ES.2018.23.15.17-00336

[21] S. Caini, K. Szomor, E. Ferenczi et al., Tick-borne encephalitis transmitted by unpasteurised cow milk in western Hungary, September to October 2011, Euro Surveill 17(12) (2012) 20128.

[22] J. Cimperman, V. Maraspin, S. Lotric-Furlan et al., Concomitant infection with tick-borne encephalitis virus and Borrelia burgdorferi sensu lato in patients with acute meningitis or meningoencephalitis, Infection. 26(3) (1998) 160-164.

[23] E. Dorko, J. Hockicko, K. Rimarova et al., Milk outbreaks of tick-borne encephalitis in Slovakia, 2012-2016. Cent. Eur. J. Public Health 26(Suppl) (2018) S47-S50. Retrieved from: https://doi.org/10.21101/cejph.a5272

[24] J. Kerlik, M. Avdičova, M. Štefkovičova et al., Slovakia reports highest occurrence of alimentary tick-borne encephalitis in Europe: analysis of tickborne encephalitis outbreaks in Slovakia during 2007-2016, Travel. Med. Infect. Dis. 26 (2018) 37-42. Retrieved from: https://doi.org/10.1016/j. tmaid.2018.07.001

[25] M.E. Krol, B. Borawski, A. Nowicka-Ciełuszecka et al., Outbreak of alimentary tick-borne encephalitis in Podlaskie voivodeship, Tick-borne encephalitis in Russia and Europe MA 2(67) (2021) 19, Poland, Przegl Epidemiol. 73(2) (2019) 239-224. Retrieved from: https://doi.org/10.32394/pe.73.01

[26] D. Krzyczmanik, M. Rybacki, T. Wittczak et al., Coexistence of two occupational infectious diseases in one patient - borreliosis and tick-borne encephalitis - a case report, Med. Pr. 62(3) (2011) 339-344.

[27] J. Oksi, M.K. Viljanen, H. Kalimo et al., Fatal encephalitis caused by concomitant infection with tick-borne encephalitis virus and Borrelia burgdorferi, Clin. Infect. Dis. 16(3) (1993) 392 396. DOI:10.1093/clind/16.3.392
[28] K.M. Paulsen, S. Snorre et al., Tick-borne encephalitis virus in cows and unpasteurized cow milk from Norway, Zoonoses Public Health 66(2) (2019) 216-222. Retrieved from: https://doi.org/10.1111/zph.12554

[29] J. Salat, A.D. Mihalca, M. Mihaiu et al., TickBorne encephalitis in Sheep, Romania, Emerg. Infect. Dis. 23(12) (2021) 2065-2067. Retrieved from: https://doi.org/10.3201/eid2312.170166 